\title{
Changes in cell junctions induced by inhibition of epidermal growth factor receptor in oral squamous cell carcinoma cells
}

\author{
YASUMASA KAKEI* ${ }^{*}$, SHUN TERAOKA* , MASAYA AKASHI, TAKUMI HASEGAWA and TAKAHIDE KOMORI \\ Department of Oral and Maxillofacial Surgery, Kobe University Graduate School of Medicine, Kobe, Hyōgo 650-0017, Japan
}

Received November 9, 2016; Accepted March 17, 2017

DOI: $10.3892 /$ etm.2017.4606

\begin{abstract}
The benefits of epidermal growth factor receptor (EGFR) targeting in the treatment of head and neck cancer, have been documented. However, a minority of patients with head and neck cancer are unresponsive to EGFR targeting therapies. The present study evaluated the effects and limitations of an EGFR inhibitor on oral squamous cell carcinoma cells, particularly on cell-cell junctions mediated by epithelial (E)-cadherin. HSC-3 oral squamous cell carcinoma cells were treated with the EGFR inhibitor, $\operatorname{AG} 1478$ (0, 0.5, 2, 10 and $50 \mu \mathrm{M}$ ), and the effects of EGFR inhibition in HSC-3 cells were evaluated by wound healing assays, E-cadherin immunostaining and measurement of transepithelial electrical resistance in vitro. It was observed that treatment of oral squamous cell carcinoma cells with AG1478 suppressed cell motility, altered cell morphology and increased the number of cell-cell junctions compared with untreated control cells. Knockdown of EGFR induced a similar phenotype to that observed by the inhibition of EGFR. Furthermore, in oral squamous cell carcinoma cells treated with high-dose EGFR inhibitor $(50 \mu \mathrm{M})$, the small number of cells that survived formed cell-cell junctions that were positive for E-cadherin expression. In cells treated with low concentrations of EGFR inhibitor $(2 \mu \mathrm{M})$, recovery of epithelial properties was observed. The retention of E-cadherin expression in cells that survived high-dose EGFR inhibitor treatment may be a survival mechanism of cancer cells.
\end{abstract}

\section{Introduction}

Head and neck cancer is the sixth most prevalent malignancy and is increasing in frequency worldwide (1). The most

Correspondence to: Dr Masaya Akashi, Department of Oral and Maxillofacial Surgery, Kobe University Graduate School of Medicine, 7-5-2 Kusunoki-cho, Kobe, Hyōgo 650-0017, Japan E-mail: akashim@med.kobe-u.ac.jp

*Contributed equally

Key words: epithelial cadherin, zonula occludens-1, epidermal growth factor receptor, cell junctions, oral squamous cell carcinoma common site for head and neck cancer is the oral cavity, with $40 \%$ of cases occurring in this region (2). Despite improvements in surgery, radiation and chemotherapy, treatment of oral squamous cell carcinoma (OSCC) remains a challenge. Although OSCC has been extensively studied (3), the molecular characteristics of this malignancy remain unknown.

A decrease in epithelial cell adhesion is a key step in the progression and metastasis of tumors (4). The loss of epithelial differentiation and gain of a mesenchymal phenotype, known as epithelial-to-mesenchymal transition, is associated with malignant transformation in numerous carcinomas (5), and may be a predictor of OSCC progression and prognosis $(6,7)$.

The epithelial junctional complex is composed of tight junctions, adherens junctions and desmosomes. Cadherins are major components of adherens junctions and serve a key role in the maintenance of epithelial tissue integrity (8). The transmembrane protein epithelial (E)-cadherin is a widely distributed, intercelluar adhesion molecule (9) that, through its cytoplasmic tail, associates with various intracellular proteins, including with vari (10). Loss of E-cadherin expression is typically observed in carcinomas (11), and in breast cancer, transfection with ectopic E-cadherin has been demonstrated to decrease the invasiveness of cancer cells (12).

Epidermal growth factor receptor (EGFR) is a member of the receptor tyrosine kinase family, and overexpression of EGFR has been documented in OSCC (13). Stimulation of EGFR induces intrinsic tyrosine kinase activity and cellular signaling, resulting in cell growth and proliferation (14). EGFR stimulation is also associated with perturbation of E-cadherin-mediated cell adhesion, morphological fibroblast-like changes and increased cell motility in tumors (15), due to association of EGFR with the cadherin-catenin complex (16).

Targeting of EGFR signaling is a potential therapy for the treatment of many cancers, including non-small-cell lung cancer and colorectal cancer $(17,18)$. Specific drugs, such as erlotinib and gefitinib, reversibly inhibit the EGFR tyrosine kinase domain by competitively binding with adenosine triphosphate, while monoclonal antibodies, such as cetuximab and panitumumab, block ligand binding to the extracellular domain of EGFR and promote receptor internalization (18). In recurrent or metastatic head and neck SCCs, it has been observed that cetuximab in combination with chemotherapy improved overall survival (19). Cetuximab combined with high-dose radiotherapy has also been demonstrated to improve 
locoregional control in locoregionally advanced head and neck SCCs (20). Despite the benefits of EGFR-targeting agents, a minority of patients with head and neck cancer are unresponsive to EGFR targeting therapies. Therefore, studies are required to elucidate the underlying molecular mechanisms regarding the effects of EGFR inhibition in cancer cells. The present study aimed to evaluate the effect of EGFR inhibition on OSCC cells, particularly on cell-cell junctions mediated by cadherin, by performing wound healing, E-cadherin immunostaining and transepithelial resistance assays in OSCC cells treated with EGFR inhibitor (AG1478) or EGFR small interfering RNA (siRNA). The efficacy and limitations of EGFR-targeted therapies were also evaluated.

\section{Materials and methods}

Cell culture. The human HSC-3 OSCC cell line was obtained from the National Institute of Biomedical Innovation (Osaka, Japan). HSC-3 cells were cultured in high glucose Dulbecco's modified Eagle's medium (DMEM) supplemented with L-glutamine and Phenol Red (Wako Pure Chemical Industries, Ltd., Osaka, Japan), 10\% fetal bovine serum and 1\% penicillin/streptomycin (Sigma-Aldrich; Merck KGaA, Darmstadt, Germany) at $37^{\circ} \mathrm{C}$ in a humidified atmosphere of $5 \% \mathrm{CO}_{2}$. Cells were incubated in DMEM for 24-48 h prior to treatment. Early passages of cells (between 2 and 10 passages from the stage of primary culture) were used in the current study.

Reagents and antibodies. Rat anti-E-cadherin monoclonal antibody (ECCD2) was purchased from Takara Bio, Inc. (Otsu, Japan) and the EGFR inhibitor AG1478 was obtained from Merck KGaA. Mouse anti-zonula occludens (ZO)-1 monoclonal antibody (T8-754) was characterized as described previously (21). Rabbit anti-EGFR monoclonal antibody (D38B1) was purchased from Cell Signaling Technology, Inc. (Danvers, MA, USA). Secondary antibodies conjugated with Alexa Fluor ${ }^{\circledR} 488$ donkey anti-rabbit IgG (H+L; A11059) and $\mathrm{Cy}^{\circledR} 3$ donkey anti-mouse $\mathrm{IgG}(\mathrm{H}+\mathrm{L}$; AP192C) were purchased from Invitrogen (Thermo Fisher Scientific, Inc., Waltham, MA, USA).

RNA interference (RNAi) experiments. The following Stealth $\mathrm{RNAi}^{\mathrm{TM}}$ small interfering (si)RNA (Invitrogen; Thermo Fisher Scientific, Inc.) was used for RNAi experiments: Human EGFR-EGFRHSS103116, 5'-CCUAUGCCUUAG CAGUCUUAUCUAA-3'. A Stealth RNAi ${ }^{\text {TM }}$ siRNA negative control (Invitrogen; Thermo Fisher Scientific, Inc.) was used for control experiments. Transfection of HSC-3 cells with the siRNAs was performed using a Lipofectamine ${ }^{\circledR}$ RNAi MAX reagent according to the manufacturer's protocol. (Invitrogen; Thermo Fisher Scientific, Inc.).

Western blot analysis. Cells were lysed with lysis buffer containing 0.5 M Tris- $\mathrm{HCl}$ (pH 6.8), 10\% SDS and glycerol, and $1 \mathrm{M}$ dithiothreitol was added to cell lysates prior to loading at room temperature. siRNA-treated cells were lysed in the same way. A total of $20 \mu \mathrm{g}$ protein were loaded on $10 \%$ SDS-PAGE gels. Protein mobility was assessed using Precision Plus Protein ${ }^{\mathrm{TM}}$ Dual Color Standards (Bio-Rad Laboratories, Inc., Hercules, CA, USA). Protein bands were transferred to
Immnobilon-P polyvinylidene difluoride membranes (Merck $\mathrm{KGaA}$ ) and incubated with rabbit anti-EGFR monoclonal antibody (D38B1; 1:1,000) and rabbit anti-GAPDH polyclonal antibody (ab9485; 1:2,500; Abcam, Cambridge, UK) for $24 \mathrm{~h}$ at $4^{\circ} \mathrm{C}$, followed by incubation with corresponding horseradish peroxidase-conjugated goat anti-rabbit $\operatorname{IgG}(\mathrm{H}+\mathrm{L})$ secondary antibody (31460; Invitrogen; Thermo Fisher Scientific, Inc.) for $1 \mathrm{~h}$ at room temperature. Immunostained bands were developed using an enhanced chemiluminescence system (GE Healthcare Life Sciences, Chalfont, UK). Blots were scanned with a LAS-3000 mini imaging system (Fujifilm, Tokyo, Japan). GAPDH was used as an internal loading control. The experiment was repeated three times.

Immunofluorescence staining and microscopy. Cells were grown with DMEM on microcover glass slips in $35 \times 10 \mathrm{~mm}$ polystyrene tissue culture dishes at a density of $1 \times 10^{5}$ cells $/ \mathrm{ml}$ for $24 \mathrm{~h}$. The cells were fixed with $1 \%$ formaldehyde in phosphate-buffered saline (PBS) for $10 \mathrm{~min}$ at room temperature, then treated with $0.2 \%$ Triton X-100 in PBS for 5 min at room temperature and washed with PBS. The cells were blocked with $1 \%$ bovine serum albumin (Sigma-Aldrich; Merck KGaA) in PBS for $30 \mathrm{~min}$ at room temperature, then incubated with primary antibodies (rat anti-E-cadherin monoclonal antibody, mouse anti-ZO-1 monoclonal antibody, and rabbit anti-EGFR monoclonal antibody, as mentioned above) for $24 \mathrm{~h}$ at $4^{\circ} \mathrm{C}$. All antibodies were diluted with $1 \%$ bovine serum albumin in PBS as mentioned above. The cells were then rinsed three times with PBS and incubated with corresponding secondary antibodies (1:500; Alexa Fluor ${ }^{\circledR} 488$ and $\mathrm{Cy} 3^{\circledR}$ ) for $30 \mathrm{~min}$ at room temperature. After rinsing with PBS, specimens were embedded in FluorSave ${ }^{\mathrm{TM}}$ (Merck KGaA) and observed with an IX71 fluorescence microscope (Olympus Soft Imaging Solutions GmbH, Münster, Germany). Images were captured using a combined ORCA-ER cooled CCD camera (Hamamatsu Photonics K.K., Shizuoka, Japan). For dose-dependent AG1478 experiments, immunofluorescence staining was performed $24 \mathrm{~h}$ after the addition of $\mathrm{AG} 1478(0,0.5,2$ and $50 \mu \mathrm{M})$ to $80 \%$ confluent HSC-3 cells.

Quantification of cell number and cell-cell junctions. Cells were immunostained following AG1478 treatment $(0,0.5,2$, 10 and $50 \mu \mathrm{M}$ ) for $24 \mathrm{~h}$, and the number of cells was counted in five randomly selected, independent microscopic images (magnification, x20). For quantification of cell junctions, the numbers of cell-cell borders involving co-expression of E-cadherin and ZO-1 were counted in five randomly selected, independent microscopic images (magnification, x20). Results are representative of five independent experiments.

Measurement of transepithelial resistance.Aliquots containing $1 \times 10^{5}$ cells $/ \mathrm{cm}^{2}$ were plated onto Transwell filters $(12 \mathrm{~mm}$ in diameter; six filters for each cell treatment group) and cultured in serum-free DMEM for 3 days until a confluent layer was formed. Transepithelial resistance (TER) measurements were performed with a Millicell-ERS electrical resistance meter (Merck KGaA) (22) immediately prior to and following the addition of $\mathrm{AG} 1478(0,0.5$ and $2 \mu \mathrm{M})$ at given time points (24, 48 and $72 \mathrm{~h}$ ). Resistance ( $\triangle \mathrm{TER})$ of the HSC-3 layers was calculated as the mean resistance of control inserts (without 

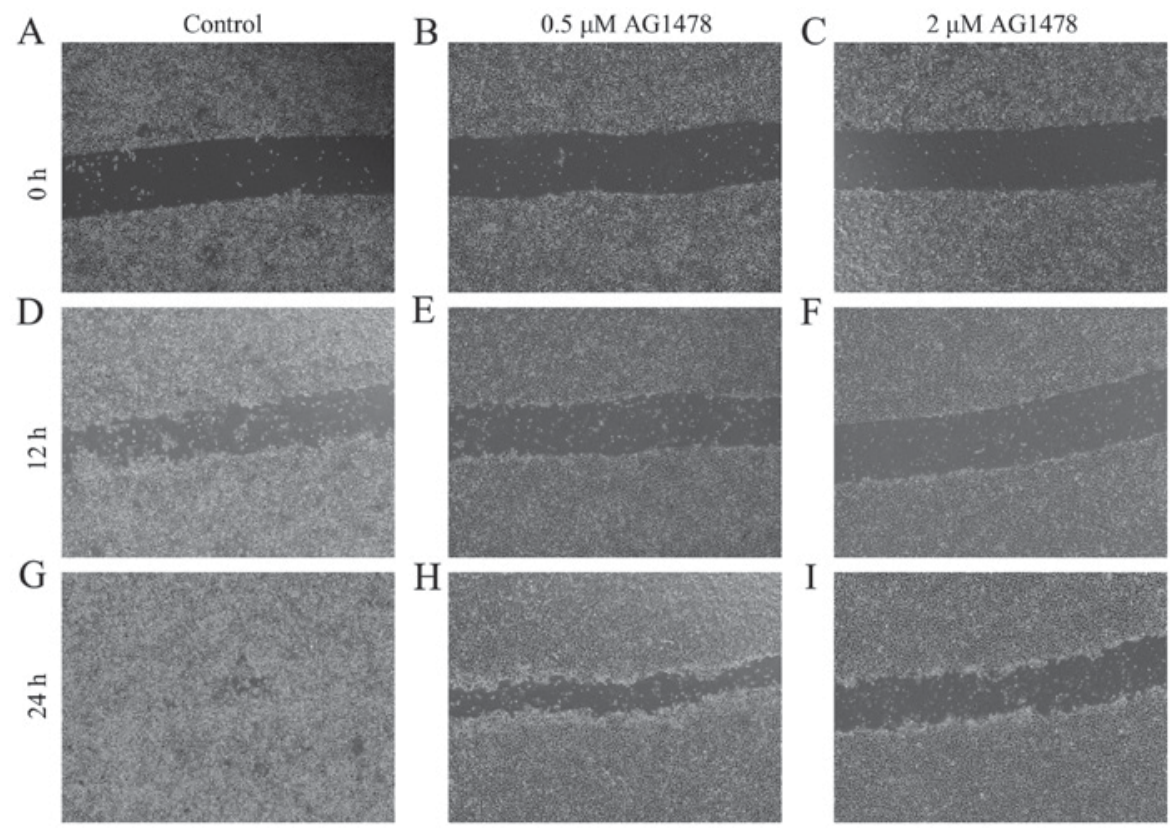

Figure 1. In vitro wound healing assay to determine HSC-3 cell motility following AG1478 treatment. AG1478 suppressed HSC-3 cell motility in a dose-dependent manner. Representative images of HSC-3 cells treated with AG1478 (0.5 and $2 \mu \mathrm{M}$ ) and control cells after (A-C) 0 , (D-F) 12 and (G-I) 24 h are shown. Magnification, $\mathrm{x} 4$.

cells, $n \geq 4$ ) subtracted from the mean resistance of cells treated with various concentrations of AG1478 at given time points (results were representative of $\geq 4$ experiments).

In vitro wound healing assay. Cells $\left(0.3 \times 10^{6}\right.$ cells $\left./ \mathrm{ml}\right)$ were plated in duplicate in 6-well plates, grown to $100 \%$ confluence, and incubated with high glucose DMEM containing AG1478 $(0,0.5$ and $2 \mu \mathrm{M})$. After $24 \mathrm{~h}$, cell monolayers were scraped with a sterile $200-\mu 1$ disposable plastic pipette tip and washed with PBS. The process of wound healing was observed by microscopy for 0,12 and $24 \mathrm{~h}$ at $37^{\circ} \mathrm{C}$ after wounding, and images were obtained using a BZ-X700 fluorescence microscope (Keyence Corporation, Osaka, Japan). Magnifications used were $\mathrm{x} 4$ for analyzing the wound healing assay and $\mathrm{x} 20$ in fluorescence microscopy.

Statistical analysis. Statistical analyses were performed using R software (R Development Core Team, 2011). The Kruskal-Wallis test with Steel-Dwass multiple comparisons was performed to compare the three groups. $\mathrm{P}<0.05$ was considered to indicate a statistically significant significance. Data were presented as mean \pm standard deviation.

\section{Results}

Determination of the optimal concentration of AG1478. Previous studies using specific EGFR inhibitors have used relatively high concentrations of EGFR inhibitor. For instance, oral and pancreatic cancer cell lines have previously been treated with 20 (14) and $10 \mu \mathrm{M}$ AG1478 (23) respectively. However, treatment with high concentrations of EGFR inhibitor may be considered inappropriate for detailed observations of cell junctions, due to the induction of cytotoxic effects. Previous studies have demonstrated that AG1478 (0-32 $\mu \mathrm{M})$ inhibits cell growth in a dose-dependent manner, with lower concentrations of AG1478 (8 $\mu \mathrm{M})$ having little inhibitory effect on cell growth (24). A study using serial concentrations of AG1478 $(0-40 \mu \mathrm{M})$ to treat human breast cancer cells treated with for $72 \mathrm{~h}$ also documented that $20 \mu \mathrm{h}$ AG1478 did not induce significant apoptosis, relative to control cells, while $40 \mu \mathrm{M}$ AG1478 induced significant apoptosis (25). It was also observed that few cells survived at the higher concentration of AG1478 $(40 \mu \mathrm{M})(25)$. To determine the optimal concentration of AG1478 for use in the current study, the growth of HSC-3 cells following treatment with AG1478 (0, 0.5, 2, 10 and $50 \mu \mathrm{M}$ ) for $24 \mathrm{~h}$ was assessed by cell counting. Analogous to previous reports (24), cytotoxic effects were observed in HSC-3 cells following treatment with $50 \mu \mathrm{M}$ AG1478, while lower concentrations of AG1478 (0-10 $\mu \mathrm{M})$ had little inhibitory effect on cell growth (data not shown).

AG1478 suppresses cell motility. The integrated biological responses to EGFR signaling are pleiotropic, resulting in tumor-promoting cellular activities, including enhancement of cell motility and cytoskeletal changes (26). Therefore, the current study evaluated the motility of HSC-3 cells following treatment with AG1478 $(0.5$ and $2 \mu \mathrm{M})$ for 12 and $24 \mathrm{~h}$. In vitro wound healing assays indicated that AG1478 treatment $(2 \mu \mathrm{M})$ suppressed the motility of the OSCC cell line, relative to untreated control cells (Fig. 1).

Morphological changes of HSC-3 cells following AG1478 treatment. The expression pattern of E-cadherin in HSC-3 cells treated with AG1478 (0.5 and $2 \mu \mathrm{M})$ was subsequently determined. It was observed that AG1478 treatment altered the cellular morphology of HSC-3 cells in a dose-dependent manner (Fig. 2). Control HSC-3 cells exhibited a spindle-shaped fibroblastic cellular morphology, and prominent spaces were observed between cells (Fig. 2A). Treatment of cells with $0.5 \mu \mathrm{M}$ AG1478 flattened the fibroblastic morphology of 

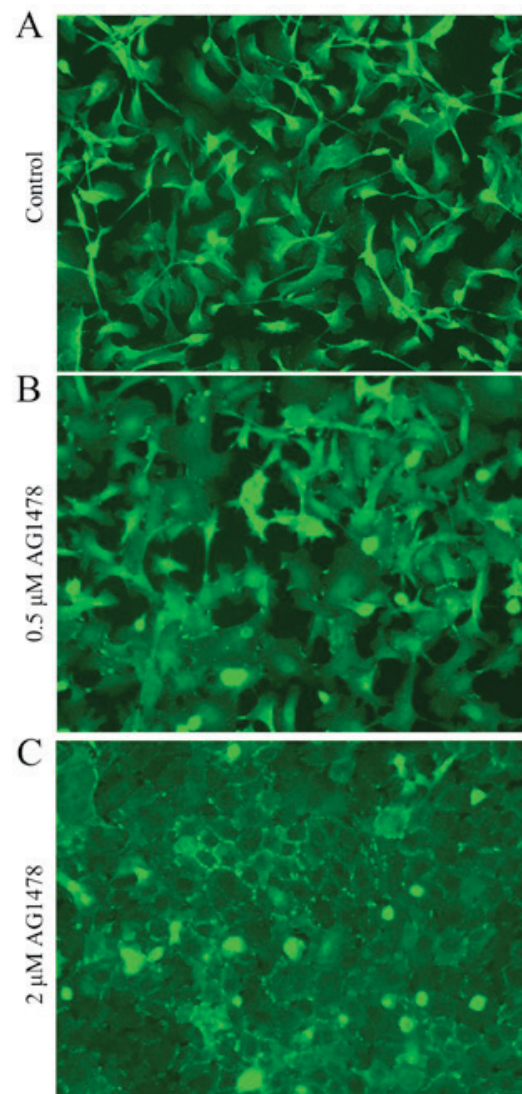

Figure 2. Immunofluorescence staining of epithelial cadherin (green). Treatment of HSC-3 cells with AG1478 altered cytoskeletal morphology in a dose-dependent manner. (A) The spindle shape of untreated HSC-3 cells was altered to a (B) flattened and (C) epithelial-like squamous morphology by 0.5 and $2 \mu \mathrm{M}$ AG1478, respectively. The spaces between cells decreased following AG1478 treatment in a dose-dependent manner. Magnification, $\mathrm{x} 20$.
HSC-3 cells (Fig. 2B), and the higher concentration of AG1478 $(2 \mu \mathrm{M})$ caused cells to adopt an epithelial-like squamous morphology (Fig. 2C). Relative to all other concentrations of AG1478 investigated $(0-50 \mu \mathrm{M}), 2 \mu \mathrm{M}$ AG1478 reduced the spaces between cells to the greatest extent. Immunostaining of cell-cell contacts demonstrated that AG1478 altered the expression of E-cadherin and the tight junction-associated cytoplasmic protein ZO-1, as a marker of cell junctions in various cell types (27), in a dose-dependent manner. In control HSC-3 cells, E-cadherin and ZO-1 were not consistently colocalized, due to the absence of ZO-1 and E-cadherin accumulations at the cell periphery and cell-cell contacts, respectively (Fig. 3A). Treatment of cells with AG1478 $(0.5 \mu \mathrm{M})$ induced the formation of punctate cell-cell junctions, indicated by discontinuous zig-zag accumulations of E-cadherin and ZO-1 at cell-cell contacts (Fig. 3B). Treatment with the higher concentration of AG1478 $(2 \mu \mathrm{M})$ led to the formation of continuous linear junctions, indicated by linear accumulations and co-expression of E-cadherin and ZO-1 (Fig. 3C), which appeared similar to cell junctions in normal squamous epithelial cells. The number of cell junctions (i.e., the numbers of cell-cell borders involving co-expression of E-cadherin and ZO-1) significantly increased in a dose-dependent manner $(\mathrm{P}<0.05$; Fig. 4A).

AG1478 increases TER. TER was also investigated as an index of epithelial barrier function. It was observed that AG1478 $(0.5$ and $2 \mu \mathrm{M})$ increased TER in a dose-dependent manner (Fig. 4B), despite having no effect on total cell number (data not shown).

EGFR knockdown induces morphological changes in HSC-3 cells. Similar to AG1478 treatment, knockdown of EGFR
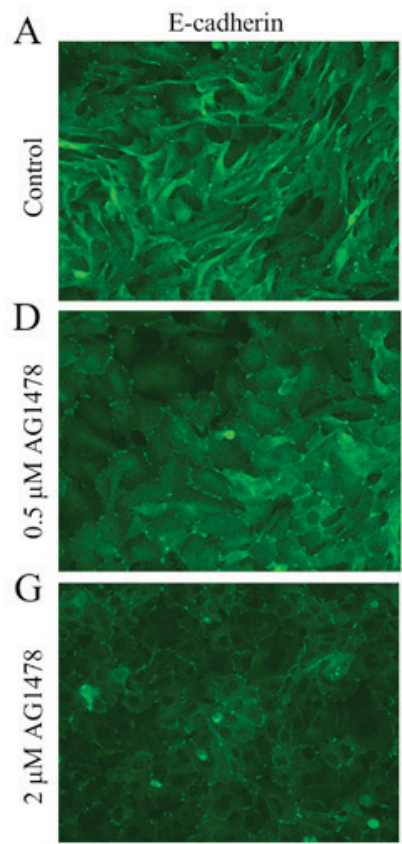

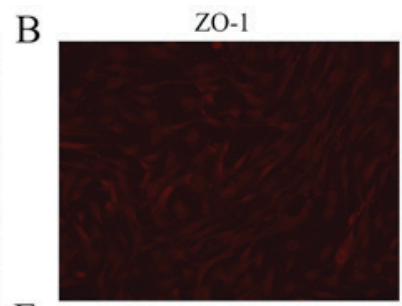

E

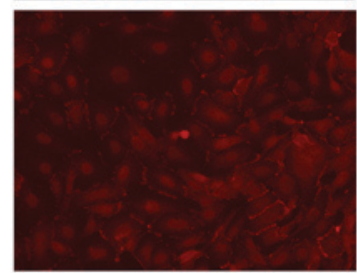

$\mathrm{H}$

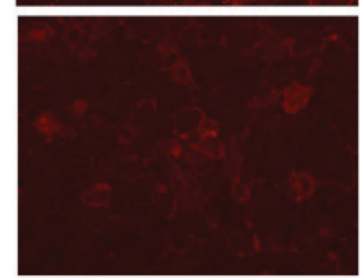

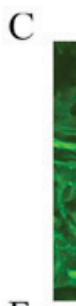

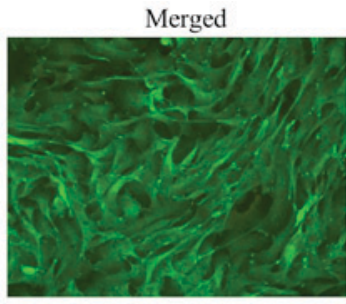

$\mathrm{F}$
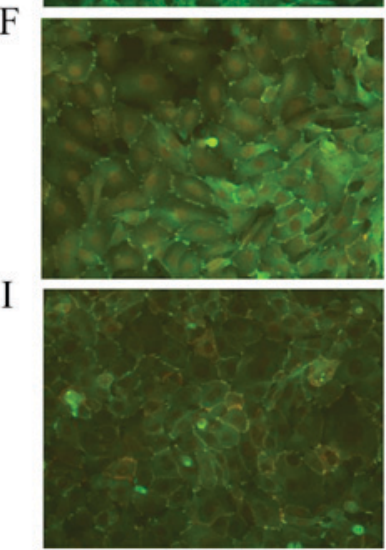

Figure 3. Double immunofluorescence staining of E-cadherin (green) and ZO-1 (red). Treatment of HSC-3 cells with AG1478 altered cell-cell junctions in a dose-dependent manner. (A-C) In control HSC-3 cells, the expression of cell-junction proteins at the cell periphery was absent. (D-F) Treatment with $0.5 \mu \mathrm{M}$ AG1478 induced the formation of punctate cell-cell junctions, indicated by a discontinuous zig-zag accumulation of cell junction proteins at cell-cell contact sites. (G-I) Treatment with $2 \mu \mathrm{M}$ AG1478 led to the formation of continuous linear junctions, indicated by linear accumulations and co-expression of E-cadherin and ZO-1. Magnification, x20. E-cadherin, epithelial cadherin; ZO-1, zonula occludens-1. 
A

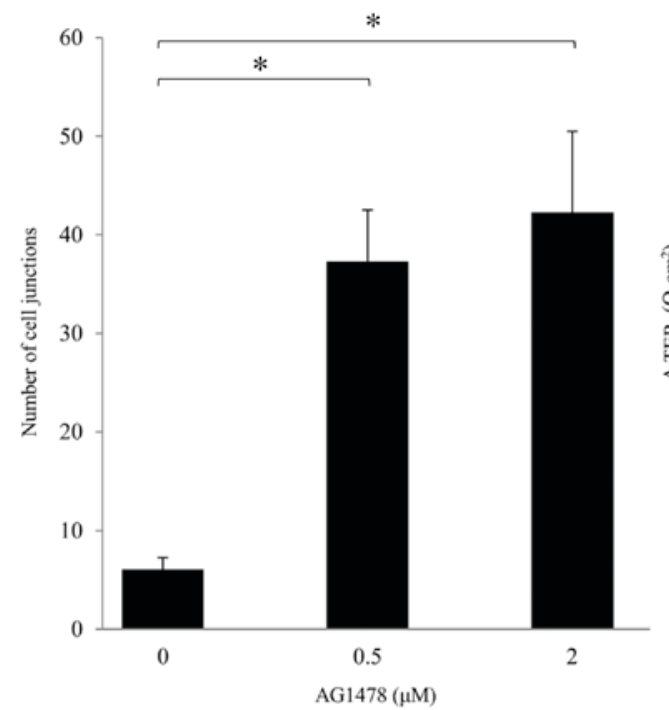

B

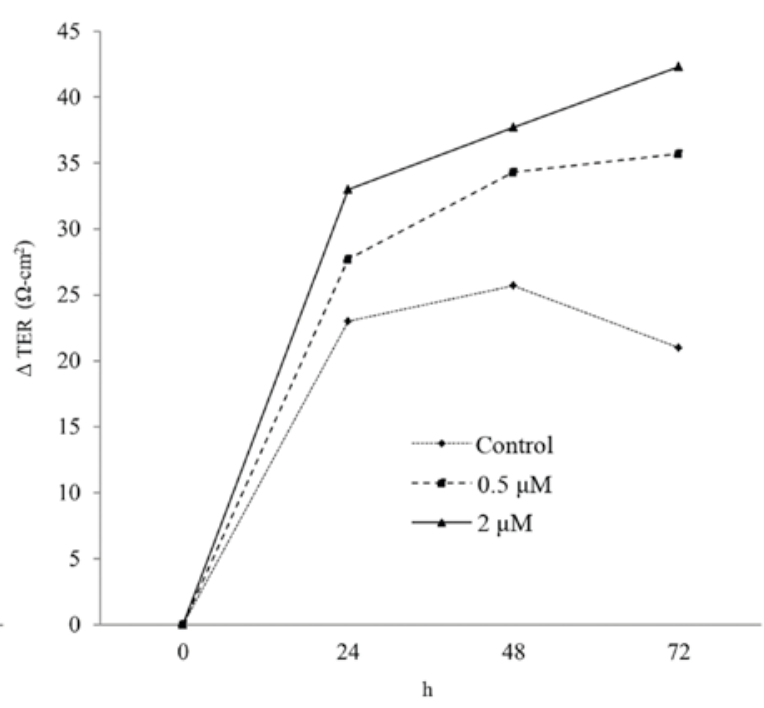

Figure 4. E-cadherin-positive cell junctions and TER in HSC-3 cells following AG1478 treatment. (A) The number of cells exhibiting E-cadherin-positive cell junctions and (B) TER increased following AG1478 treatment in a dose-dependent manner. E-cadherin, epithelial cadherin; TER, transepithelial resistance. "P $<0.05$.
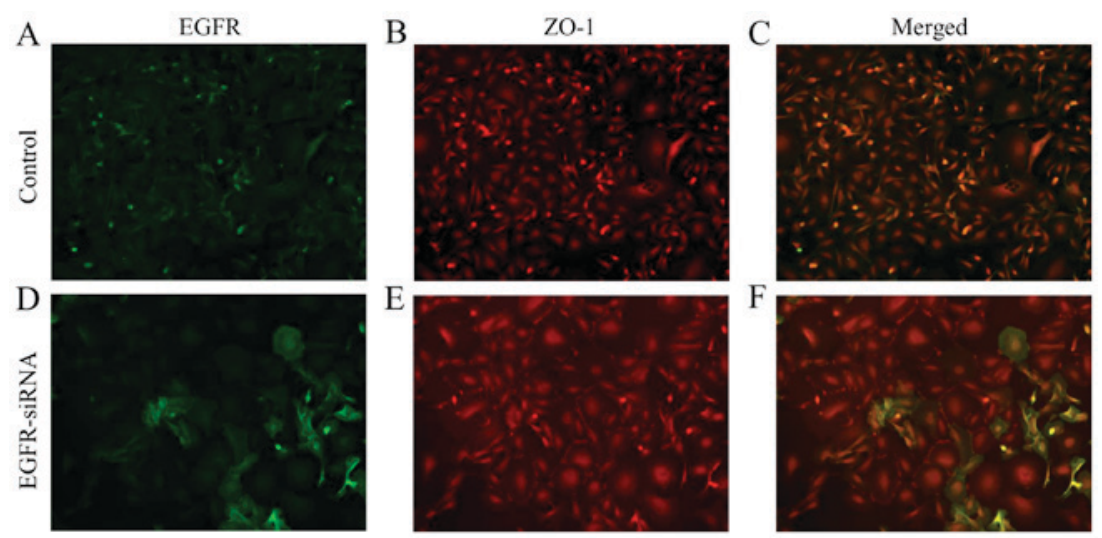

G

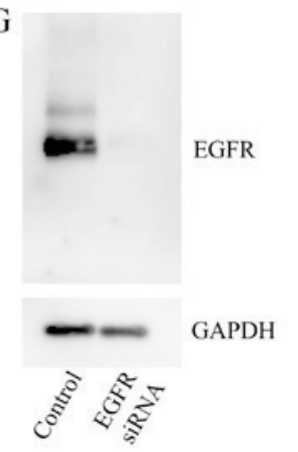

Figure 5. Double immunofluorescence staining of EGFR and ZO-1. (A-C) The spindle shape of untreated HSC-3 cells was altered to a (D-F) flattened morphology by knockdown of EGFR with siRNA. (G) Western blot analysis indicated that siRNA against EGFR successfully suppressed EGFR expression in HSC-3 cells. Magnification, x20. EGFR, epidermal growth factor receptor; siRNA, small interfering RNA; ZO-1, zonula occludens-1.

flattened the fibroblastic morphology of HSC-3 cells (Fig.5A-C), relative to untransfected control cells (Fig. 5D-F), indicating an epithelial-like squamous cell phenotype.

High-dose AG1478 treatment reduces the number of HSC-3 cells. Finally, the phenotype of HSC-3 cells following high-dose AG1478 $(50 \mu \mathrm{M})$ treatment was assessed by immunostaining (Fig. 6). High dose AG1478 caused a marked reduction in the number of HSC-3 cells, relative to untreated controls and cells treated with $2 \mu \mathrm{M}$ AG1478. In addition, E-cadherin accumulation and co-expression with EGFR at the cell-cell boundaries was retained in a number of the surviving cells. However, isolated cells lacking cell-cell adhesion were also observed. 

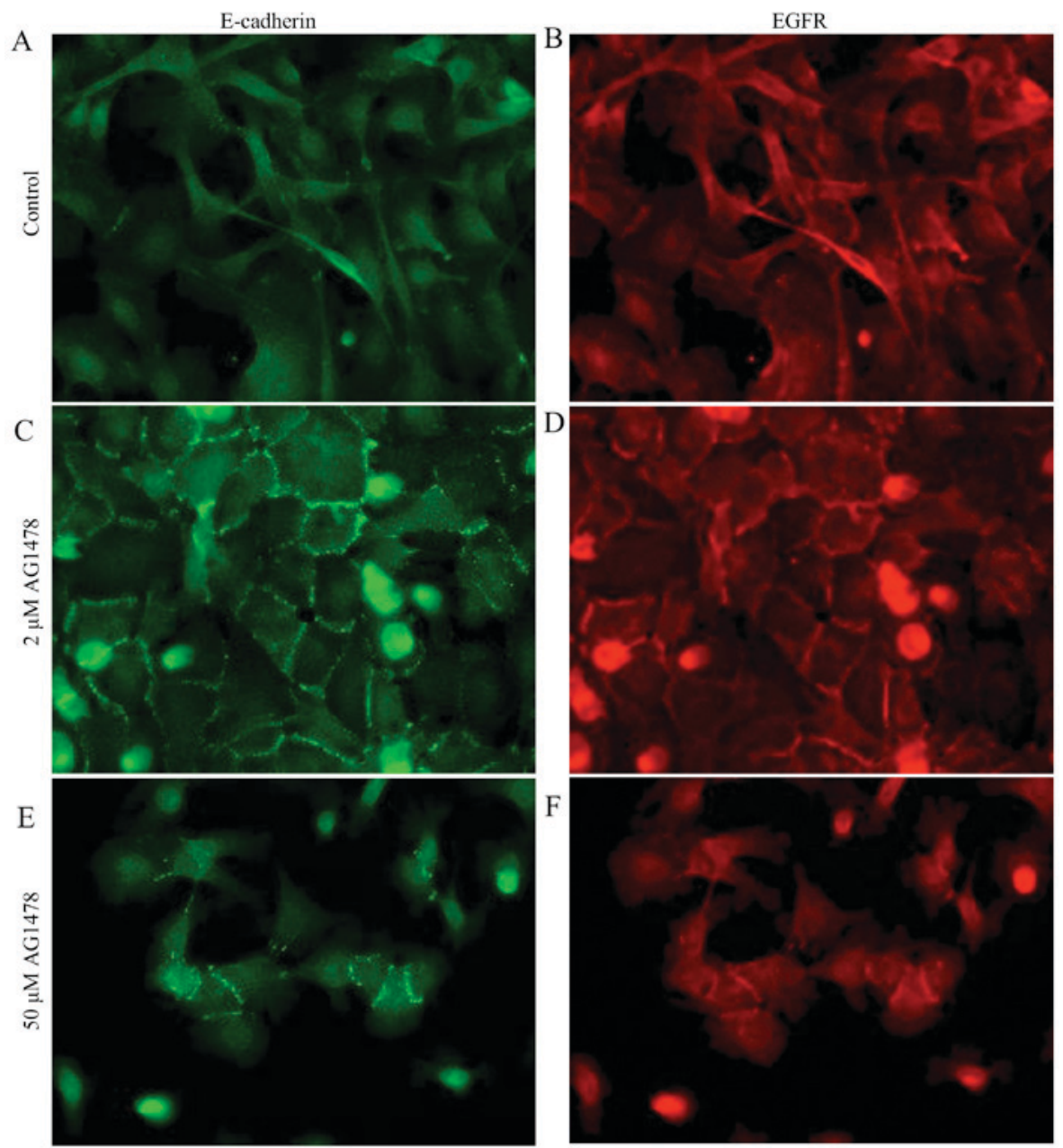

Figure 6. Double immunofluorescence staining of E-cadherin (green) and EGFR (red). (A-D) In HSC-3 cells treated with $2 \mu$ M AG1478 and untreated controls, accumulation and co-expression of E-cadherin with EGFR at the cell-cell boundaries was observed. (E and F) Cells that survived high-dose AG1478 treatment $(50 \mu \mathrm{M})$ retained E-cadherin junctions and coexpression between E-cadherin and EGFR. Magnification, x20. E-cadherin, epithelial cadherin; EGFR, epidermal growth factor receptor.

\section{Discussion}

Overexpression of EGFR has been documented in OSCC $(28,29)$. EGFR signaling is associated with a loss of cell adhesion mediated by E-cadherin and acquisition of a fibroblast-like cellular morphology, which subsequently increases cell motility and potentially serves a role in tumor invasion and metastasis $(14,30,31)$. In the present study, morphological changes in HSC-3 cells and reductions in cell motility were observed following EGFR inhibition. Treatment of cells with a low concentration of EGFR inhibitor induced the formation of cell-cell junctions, indicated by an accumulation of E-cadherin and ZO-1 at cell-cell contacts and strengthening of barrier function. Suppression of EGFR expression by siRNA also induced cellular morphological changes and accumulation of E-cadherin at cell-cell contacts. The HSC-3 cells used in the present study are generally poorly differentiated cells with a random morphology, have exhibit a limited ability to form cell junctions within monolayer cultures (32). Previous studies using HSC-3 cells have documented low-level activation of EGFR within cells grown in monolayer cultures, and an infrequent colocalization of phosphorylated EGFR and
E-cadherin (33). It has also been suggested that other pathways may activate EGFR. For instance, in the process of cell adhesion, integrins bind to extracellular matrix proteins, which in turn may stimulate multiple pathways that modulate actin cytoskeletal organization and cell motility (34). In response to cell-matrix adhesion, a complex involving integrins and EGFR is formed, and EGFR is subsequently phosphorylated on tyrosines 845, 1068, 1086 and 1173, though not on 1148 (34). Phosphorylation of EGFR at tyrosine 1173 has been associated with a poor prognosis in OSCC (26). These results indicate that treatment of HSC-3 cells with low concentrations of EGFR inhibitor may affect integrin-mediated signaling pathways and consequently alter cytoskeletal morphology and cell motility.

It was also observed in the current study that HSC-3 cells with cell-cell junctions positive for E-cadherin were able to survive high-dose EGFR inhibitor treatment. Previous reports have demonstrated that inhibition of EGFR kinase activity with tyrosine kinase inhibitors typically leads to decreased cell proliferation without affecting cell survival (35), while targeted knockdown of the EGFR protein has been found to result in cell death (36). Cell death induced by EGFR knockdown may be due to autophagy and not typical apoptosis (37). 
Autophagy, a process of intracellular proteolysis, is induced in various cancer cell lines, including those for non-small-cell lung cancer and colorectal cancer, following treatment with EGFR tyrosine kinase inhibitors in a dose-dependent manner; however, autophagy is not activated in cells that exhibit resistance to EGFR inhibitors (38). Inhibition of tyrosine kinase activity alone has limited therapeutic efficacy, possibly due to the inhibitory effects of EGFR on autophagy in various cancer cell lines, which are potentially independent of its tyrosine kinase activity (37). A previous study in ovarian cancer cells observed that epidermal growth factor induced a downregulation in E-cadherin expression and increased the invasiveness of cancer cells (39). In head and neck SCC cells overexpressing E-cadherin, it has also been documented that a reduction in E-cadherin expression may lead to an upregulation in EGFR transcription, suggesting that loss of E-cadherin may induce proliferation by activating EGFR (40). Furthermore, in pancreatic carcinoma cells, inhibitors of matrix metalloproteinases markedly reduced E-cadherin expression while suppressing EGFR activation, while upregulation of E-cadherin led to changes in cellular morphology, decreased cell motility and enhanced apoptotic sensitivity in response to chemotherapeutic treatment (41). In this previous study, upregulation of E-cadherin was through suppression of ZEB1, as a transcriptional repressor of E-cadherin (41). Therefore, suppression of EGFR leading to increased expression of E-cadherin at cell-cell junctions, as observed in the present study, may be mediated by ZEB1.

E-cadherin is considered to be important during the induction and progression of epithelial cancers (42). In addition, recovery of E-cadherin expression in metastatic lesions arising from E-cadherin-deficient primary tumors has been documented $(43,44)$, indicating that a mesenchymal-to-epithelial transition may occur during metastasis (45). Distant metastases exhibit equivalent or elevated levels of E-cadherin expression when compared to the primary tumors from which they originated (46). In some tumors, cadherins attenuate cell growth, while in others, they promote growth and survival of cancer cells (33). Previous studies have demonstrated that cell-cell adhesion may promote resistance to anticancer therapies, including chemotherapy and radiotherapy (47-50). Shen and Kramer (33) have suggested that cell survival mediated by E-cadherin, by the overexpression of EGFR at cell-cell adhesion sites, may render cancer cells resistant to treatment. Cell adhesion mediated by E-cadherin induces ligand-independent EGFR activation, which triggers the mitogen-activated protein kinase (MAPK) pathway and results in the inhibition of apoptosis $(26,33)$. It has been recently documented that MAPK may mediate apoptosis and autophagy in response to various stimuli through a number of downstream pathways, including p38 and c-Jun N-terminal kinase MAPK pathways (51). However, the underlying mechanisms regarding the resistance of cancer cells to apoptosis and autophagy warrant further investigation.

A limitation of the present study was the use of only one OSCC cell line. To validate findings, future studies with more differentiated cells that express higher levels of E-cadherin, such as Ca9-22 or KB cells, are required. In addition, the present study only evaluated one strategy of EGFR suppression, through the use of a specific EGFR inhibitor. Thus, future studies are warranted to investigate the efficacy of anti-EGFR antibodies such as panitumumab.

In conclusion, treatment of OSCC cells with low concentrations of EGFR inhibitor led to the acquisition of epithelial properties, as indicated by E-cadherin-mediated cell junctions, suppression of cell motility and an increase in TER. In addition, cells that survived high-dose EGFR inhibitor treatment retained high expression of E-cadherin at cell-cell boundaries. This resistance was not observed in untreated OSCC cells. Future studies into the properties of resistant cancer cells that retain E-cadherin junctions may aid to identify cancer cell survival mechanisms and treatment strategies that overcome resistance to EGFR-targeting therapies.

\section{Acknowledgements}

The authors are thankful to Dr M. Itoh for supplying the T8-754 antibody. The present study was supported by the Japan Society for the Promotion of Science, Grants-in-Aid for Young Scientists (grant no. 23792340).

\section{References}

1. Molinolo AA, Amornphimoltham P, Squarize CH, Castilho RM, Patel V and Gutkind JS: Dysregulated molecular networks in head and neck carcinogenesis. Oral Oncol 45: 324-334, 2009.

2. Sales KU, Giudice FS, Castilho RM, Salles FT, Squarize CH, Abrahao AC and Pinto DS Jr: Cyclin D1-induced proliferation is independent of beta-catenin in head and neck cancer. Oral Dis 20: e42-e48, 2014.

3. Nagpal JK and Das BR: Oral cancer: Reviewing the present understanding of its molecular mechanism and exploring the future directions for its effective management. Oral Oncol 39: 213-221, 2003.

4. Tanaka T, Iino M and Goto K: Knockdown of Sec 6 improves cell-cell adhesion by increasing $\alpha-5$-catenin in oral cancer cells. FEBS Lett 586: 924-933, 2012.

5. Christiansen JJ and Rajasekaran AK: Reassessing epithelial to mesenchymal transition as a prerequisite for carcinoma invasion and metastasis. Cancer Res 66: 8319-8326, 2006.

6. Chaw SY, Majeed AA, Dalley AJ, Chan A, Stein S and Farah CS: Epithelial to mesenchymal transition (EMT) biomarkers-E-cadherin, beta-catenin, APC and vimentin-in oral squamous cell carcinogenesis and transformation. Oral Oncol 48: 997-1006, 2012.

7. Sakamoto K, Imanishi Y, Tomita T, Shimoda M, Kameyama K, Shibata K, Sakai N, Ozawa H, Shigetomi S, Fujii R, et al: Overexpression of SIP1 and downregulation of E-cadherin predict delayed neck metastasis in stage I/II oral tongue squamous cell carcinoma after partial glossectomy. Ann Surg Oncol 19: 612-619, 2012.

8. Munshi HG, Ghosh S, Mukhopadhyay S, Wu YI, Sen R, Green KJ and Stack MS: Proteinase suppression by E-cadherin-mediated cell-cell attachment in premalignant oral keratinocytes. J Biol Chem 277: 38159-38167, 2002.

9. Takeichi M: Cadherin cell adhesion receptors as a morphogenetic regulator. Science 251: 1451-1455, 1991.

10. Nagafuchi A: Molecular architecture of adherens junctions. Curr Opin Cell Biol 13: 600-603, 2001.

11. Van Aken E, De Wever O, Correia da Rocha AS and Mareel M: Defective E-cadherin/catenin complexes in human cancer. Virchows Arch 439: 725-751, 2001.

12. Frixen UH and Nagamine Y: Stimulation of urokinase-type plasminogen activator expression by blockage of E-cadherin-dependent cell-cell adhesion. Cancer Res 53: 3618-3623, 1993

13. Forastiere AA and Burtness BA: Epidermal growth factor receptor inhibition in head and neck cancer-more insights, but more questions. J Clin Oncol 25: 2152-2155, 2007.

14. Lee $\mathrm{CH}$, Hung HW, Hung PH and Shieh YS: Epidermal growth factor receptor regulates beta-catenin location, stability, and transcriptional activity in oral cancer. Mol Cancer 9: 64, 2010. 
15. Lilien $\mathbf{J}$ and Balsamo $\mathrm{J}$ : The regulation of cadherin-mediated adhesion by tyrosine phosphorylation/dephosphorylation of beta-catenin. Curr Opin Cell Biol 17: 459-465, 2005.

16. Hoschuetzky H, Aberle $\mathrm{H}$ and Kemler R: Beta-catenin mediates the interaction of the cadherin-catenin complex with epidermal growth factor receptor. J Cell Biol 127: 1375-1380, 1994.

17. Ciardiello F and Tortora G: EGFR antagonists in cancer treatment. N Engl J Med 358: 1160-1174, 2008.

18. Chong CR and Jänne PA: The quest to overcome resistance to EGFR-targeted therapies in cancer. Nat Med 19: 1389-1400, 2013.

19. Vermorken JB, Mesia R, Rivera F, Remenar E, Kawecki A, Rottey S, Erfan J, Zabolotnyy D, Kienzer HR, Cupissol D, et al: Platinum-based chemotherapy plus cetuximab in head and neck cancer. N Engl J Med 359: 1116-1127, 2008.

20. Bonner JA, Harari PM, Giralt J, Azarnia N, Shin DM, Cohen RB, Jones CU, Sur R, Raben D, Jassem J, et al: Radiotherapy plus cetuximab for squamous-cell carcinoma of the head and neck. $N$ Engl J Med 354: 567-578, 2006.

21. Itoh M, Yonemura S, Nagafuchi A, Tsukita $S$ and Tsukita $S$ : A 220-kD undercoat-constitutive protein: Its specific localization at cadherin-based cell-cell adhesion sites. J Cell Biol 115 $1449-1462,1991$

22. Higashi T, Tokuda S, Kitajiri S, Masuda S, Nakamura H, Oda Y and Furuse M: Analysis of the 'angulin' proteins LSR, ILDR1 and ILDR2-tricellulin recruitment, epithelial barrier function and implication in deafness pathogenesis. J Cell Sci 126: 966-977, 2013

23. Takai E, Tan X, Tamori Y, Hirota M, Egami H and Ogawa M: Correlation of translocation of tight junction protein Zonula occludens-1 and activation of epidermal growth factor receptor in the regulation of invasion of pancreatic cancer cells. Int J Oncol 27: 645-651,2005.

24. Takaoka S, Iwase M, Uchida M, Yoshiba S, Kondo G, Watanabe H, Ohashi M, Nagumo M and Shintani S: Effect of combining epidermal growth factor receptor inhibitors and cisplatin on proliferation and apoptosis of oral squamous cell carcinoma cells. Int J Oncol 30: 1469-1476, 2007.

25. Zhang YG, Du Q, Fang WG, Jin ML and Tian XX: Tyrphostin AG1478 suppresses proliferation and invasion of human breast cancer cells. Int J Oncol 33: 595-602, 2008.

26. Monteiro L, Ricardo S, Delgado M, Garcez F, do Amaral B and Lopes C: Phosphorylated EGFR at tyrosine 1173 correlates with poor prognosis in oral squamous cell carcinomas. Oral Dis 20 178-185, 2014.

27. Kakei Y, Akashi M, Shigeta T, Hasegawa T and Komori T: Alteration of cell-cell junctions in cultured human lymphatic endothelial cells with inflammatory cytokine stimulation. Lymphat Res Biol 12: 136-143, 2014.

28. Störkel S, Reichert T, Reiffen KA and Wagner W: EGFR and PCNA expression in oral squamous cell carcinomas-A valuable tool in estimating the patient's prognosis. Eur J Cancer B Oral Oncol 29B: 273-277, 1993.

29. Monteiro LS, Diniz-Freitas M, Garcia-Caballero T, Forteza J and Fraga M: EGFR and Ki-67 expression in oral squamous cell carcinoma using tissue microarray technology. J Oral Pathol Med 39: 571-578, 2010

30. Hamaguchi M, Matsuyoshi N, Ohnishi Y, Gotoh B, Takeichi M and Nagai Y: p60v-src causes tyrosine phosphorylation and inactivation of the N-cadherin-catenin cell adhesion system. EMBO J 12: 307-314, 1993.

31. Shibata T, Gotoh M, Ochiai A and Hirohashi S: Association of plakoglobin with APC, a tumor suppressor gene product and its regulation by tyrosine phosphorylation. Biochem Biophys Res Commun 203: 519-522, 1994.

32. Kawano K, Kantak SS, Murai M, Yao CC and Kramer RH: Integrin alpha3beta1 engagement disrupts intercellular adhesion. Exp Cell Res 262: 180-196, 2001.

33. Shen $X$ and Kramer RH: Adhesion-mediated squamous cell carcinoma survival through ligand-independent activation of epidermal growth factor receptor. Am J Pathol 165: 1315-1329, 2004.
34. Moro L, Dolce L, Cabodi S, Bergatto E, Boeri Erba E, Smeriglio M, Turco E, Retta SF, Giuffrida MG, Venturino M, et al: Integrin-induced epidermal grow th factor (EGF) receptor activation requires c-Src and p130Cas and leads to phosphorylation of specific EGF receptor tyrosines. J Biol Chem 277: 9405-9414, 2001.

35. Harari PM and Huang SM: Combining EGFR inhibitors with radiation or chemotherapy: Will preclinical studies predict clinical results? Int J Radiat Oncol Biol Phys 58: 976-983, 2004.

36. Nagy P, Arndt-Jovin DJ and Jovin TM: Small interfering RNAs suppress the expression of endogenous and GFP-fused epidermal growth factor receptor (erbB1) and induce apoptosis in erbB1-overexpressing cells. Exp Cell Res 285: 39-49, 2003.

37. Weihua Z, Tsan R, Huang WC, Wu Q, Chiu CH, Fidler IJ and Hung MC: Survival of cancer cells is maintained by EGFR independent of its kinase activity. Cancer Cell 13: 385-393, 2008.

38. Fung C, Chen X, Grandis JR and Duvvuri U: EGFR tyrosine kinase inhibition induces autophagy in cancer cells. Cancer Biol Ther 13: 1417-1424, 2012.

39. Cheng JC, Qiu X, Chang HM and Leung PC: HER2 mediates epidermal growth factor-induced down-regulation of E-cadherin in human ovarian cancer cells. Biochem Biophys Res Commun 434: 81-86, 2013.

40. Wang D, Su L, Huang D, Zhang H, Shin DM and Chen ZG: Downregulation of E-Cadherin enhances proliferation of head and neck cancer through transcriptional regulation of EGFR. Mol Cancer 10: 116, 2011.

41. Wang F, Sloss C, Zhang X, Lee SW and Cusack JC: Membrane-bound heparin-binding epidermal growth factor like growth factor regulates E-cadherin expression in pancreatic carcinoma cells. Cancer Res 67: 8486-8493, 2007.

42. Cavallaro U and Christofori G: Cell adhesion and signalling by cadherins and Ig-CAMs in cancer. Nat Rev Cancer 4: 118-132, 2004.

43. Saha B, Chaiwun B, Imam SS, Tsao-Wei DD, Groshen S, Naritoku WY and Imam SA: Overexpression of E-cadherin protein in metastatic breast cancer cells in bone. Anticancer Res 27: 3903-3908, 2007.

44. Chao YL, Shepard CR and Wells A: Breast carcinoma cells re-express E-cadherin during mesenchymal to epithelial reverting transition. Mol Cancer 9: 179, 2010.

45. Gunasinghe NP, Wells A, Thompson EW and Hugo HJ: Mesenchymal-epithelial transition (MET) as a mechanism for metastatic colonisation in breast cancer. Cancer Metastasis Rev 31: 469-478, 2012.

46. Kowalski PJ, Rubin MA and Kleer CG: E-cadherin expression in primary carcinomas of the breast and its distant metastases. Breast Cancer Res 5: R217-R222, 2003.

47. St Croix B and Kerbel RS: Cell adhesion and drug resistance in cancer. Curr Opin Oncol 9: 549-556, 1997.

48. St Croix B, Sheehan C, Rak JW, Flørenes VA, Slingerland JM and Kerbel RS: E-Cadherin-dependent growth suppression is mediated by the cyclin-dependent kinase inhibitor p27(KIP1). J Cell Biol 142: 557-571, 1998.

49. Green SK, Frankel A and Kerbel RS: Adhesion-dependent multicellular drug resistance. Anticancer Drug Des 14: 153-168, 1999.

50. Damiano JS, Hazlehurst LA and Dalton WS: Cell adhesion-mediated drug resistance (CAM-DR) protects the K562 chronic myelogenous leukemia cell line from apoptosis induced by BCR/ABL inhibition, cytotoxic drugs, and gamma-irradiation. Leukemia 15: 1232-1239, 2001.

51. Sui X, Kong N, Ye L, Han W, Zhou J, Zhang Q, He C and Pan H: p38 and JNK MAPK pathways control the balance of apoptosis and autophagy in response to chemotherapeutic agents. Cancer Lett 344: 174-179, 2014 